non-visualization of the gall bladder at oral cholecystography are well known. In such cases examination of the patient's film may reveal a faintly outlined common bile duct or intrahepatic ducts. This provides useful information per se. It indicates (1) that the contrast medium has been taken by the patient; (2) that the medium has been $a b$ sorbed and excreted by the liver; and (3) the presence of gall-bladder disease.

In 47 consecutive patients with nonvisualization of the gall bladder and visualization of the bile ducts after a single dose of $3.0 \mathrm{~g}$ of iopanoic acid operation revealed disease of the gall bladder with calculi in every case, and in addition almost $50 \%$ of the patients had calculi in the bile ducts. This is similar to the experience reported by Melnick and Lo Curcio. ${ }^{1}$ Since the use of operative cholangiography is now routine (or should be routine) at cholecystectomy I believe that intravenous cholangiography in such patients is no longer necessary, and in view of the potential hazards of both oral and intravenous studies of the biliary tract the numbers of these investigations should be kept to a minimum. Socalled double-dose cholecystography in my experience and in the experience of others seldom provides additional information to that available from the single-dose cholecystogram provided the bile ducts are shown. Tomography may provide visualization of the bile ducts in such cases when conventional radiography fails to reveal the biliary tract. $^{2}$ If the bile ducts are not seen after a single-dose cholecystogram, then more valuable information is obtained from intravenous cholangiography.-I am, etc.,

Jervic Street Hospital,

JAMES MCNULTY

1 Melnick, G. S., and Lo Curcio, S. B., Radiology, 2 Mujahed, Z., Evans, J. A., and Whalen, J. P., Radiology, 1974. 112, i.

\section{Who Says Was it a Drug?}

SIR,-I am not usually inclined to challenge a decision made in favour of a prescribing practitioner but the circumstances reported by your legal correspondent (23 November, p. 477) under the above heading are so astonishing as to overcome my normal reluctance.

In this case (Optimax) the referees decided that the Cadbury's drinking chocolate moiety of nearly $50 \%$ was not a drug. The Divisional Court decided to quash their decision. Unlike your legal correspondent, I do not find the relevant regula-
tions either obscure or complex. Regulation $16(7)$ states that "if any substance which was not a drug was an ingredient in a preparation of which the was an ingredient in a preparation of which the
other ingredients were drugs, the.amount to be other ingredients were drugs, the amount to be
recovered shall be the price of that substance [calculated in the manner set forth in the drug tariff] together with half the amount of the dispensing fee." This not merely "contemplates" that there "may" be occasions when it is proper for the referees to look at the substance not only as a whole but also at the constituent parts-it indicates that they are at liberty to do so. Nowhere in the regulations is this liberty limited, certainly not because the preparation is marketed as a trade entity. On the preparation is marketed as a trade entity. On the contrary, regulation $16(5)$ states "their promight possibly go even further and say that the might possibly go even further and say that the
referees are obliged to consider the constituent referees are obliged to consider the constituent
parts, since by failing to do so they would also be failing to afford the Secretary of State the opportunity to recover money to which he is entitled, which is the purpose of this regulation.

For three of Her Majesty's judges to pronounce in effect that the regulation does not mean what it says, that when a preparation is referred to the as a whole they may not consider its the regulation is aimed at or that it is merely legacy of the 1930 s is nothing short of astounding. If this decision stands the way is now astounding. If decision stands the way is now open for any enterprising firm to find itself an alcohol soluble form of digoxin, put it up in whisky, and call it "Cordimax," of which $20 \mathrm{ml}$ will give the exact therapeutic equivalent of $0.25 \mathrm{mg}$ of digoxin. Any practitioner prescribing Cordimax for a patient requiring digoxin could be confident that whatever local medical committee decided the referees would be obliged to decide that it was a drug. This is precisely the sort of thing regulation $16(7)$ is designed to prevent.

Will the Secretary of State now be obliged to take this case to the House of Lords before we all find ourselves offered the opportunity of providing our N.H.S. patients with their drugs in chocolate bars, brandy, or any acceptable food or drink form that does not alter their therapeutic value? Your legal correspondent thinks there may still be trouble when the non-drug element is a nonessential ingredient of the preparation as a whole. Not if this decision stands-for that is the precise position of 50\% Cadbury's drinking chocolate in Optimax.-I am, etc.,

London W.9

A. A. LEWIS

\section{Confidentiality of Medical Records}

SIR,-Referring to the B.M.A.'s view on the inadvisibility of forwarding hospital letters and reports to insurance companies (23 November, p. 481), it is stated: "It should be remembered that hospital and consultants' reports are confidential in nature." In the matter of hospitals forwarding medical records to the Department of Health and Social Security I feel it should also be the case that general practitioners' letters to consultants are also confidential in nature.

When I was telephoned by the solicitor of a regional hospital board to ask if I would discuss a patient's condition, the patient evidently having claimed against a hospital for an injury, I naturally said that I was unable to discuss any patient with a third party unless the patient asked me to do so. You may imagine my dismay when a letter I had written to a consultant to ask his advice about this patient was quoted back to me by the regional board's solicitor.

I tried to think of ways of stopping this leak in confidentiality. I realized that not only are the hospital records the property of the D.H.S.S. but so also are all our records. In fact, it is written into our impossible contract that records shall be kept on D.H.S.S. forms, which of course remain the property of that department and are not, as I used to think, confidential to the doctor. If not a probability it is a future possibility that other Government departments can have access to patients' "confidential" records by an agreement with the D.H.S.S. even possibly nationalized industries. I have visions of a new class of unemployable young people growing up in the future because severe stress at some stage has labelled them "unstable personality" or febrile convulsions in childhood have resulted in a "possible epileptic" label. I only hope this is extremist thinking on my part.-I am, etc.,
SIR,-In a debate in the House of Londs on 20 November Lord Wells-Pestell, Government spokesman, stated that hospital social work records are the property of the local authority. ${ }^{1}$ The reconds in question are kept in relation to the social workers' functions under the N.H.S. Acts and not local government. They hold medical information and may not involve the local authority in any way or they may concern patients living in another local authority area altogether. Surely, then, they should be the property of the area health authority?

Health service social workers have never been written into N.H.S. statutes but their duties have always been a part of Health Service functions. There is nothing in the 1973 Act to suggest that these have changed, but in order to effect their transfer to local authorities they were described (clause 18(4) (a)) as being wholly or mainly employed in local authority functions. Mrs. Barbara Castle has since written that this description was made only to effect the transfer. In counsel's opinion the clause is invalid, but the Secretary of State has not chosen to take legal guidance on this point.

Clause $12(2)$ is also of questionable legal validity. It requires health authorities to obtain from local authorities the support of social workers employed on local government functions to help them carry out their functions under the Health Service Acts. There will be occasions when such support will be required, but these need not involve N.H.S. social workers appointed before April 1974 to help carry out health functions; nor staff appointed after 1 April who are mainly employed in clinical social work not connected with the 1970 Local Government Act.

The operation of clauses $18(4)(a)$ and 12(2) has caused widespread disruption of existing services and it is essential that their validity should be determined as a matter of urgency. Social workers in charge of health authority units must know who has the legal right to decide aocess to the records under their custody and control. More than that, the N.H.S. must decide whether it needs social work support outside matters which stand referred to local authority social service committees. If existing legislation does not provide for what is needed the Act should be amended to ensure that it does. -I am, etc.

FredA ClaRkE
Chairman,
Health Service Social Workers Group

Barnet, Herts

Hansard, House of Lords, 20 November 1974 col. 1061.

Urethral Strictures in Women with Cystitis

SIR,-During the past five years we have developed a method for assessing the presence of possible urethral abnormalities in women with recurrent cystitis. The urethra is normally at an angle of $18^{\circ}$ to the vertical plane and in micturition there is a steady stream. We found that a proportion of women complained also of dribbling, spraying micturition, and this group, which contained the patients with recurrent cystitis, was assessed.

The practice is situated in a village hall 
which is empty during surgery hours apart from the surgery section. The women with cystitis were instructed to use the male urinal, urinating in an erect position separating the labia, and observing the stream. The use of the male urinal avoided fears of urinating over the edge of the bowl and enabled the patient to observe her stream in seclusion.

Twenty-eight patients who were unable to aim a firm forward stream were referred to the hospital for evaluation after first excluding the presence of a prolapse or obvious abnormality. Twenty-four patients were found to have a tight urethral orifice which was dilated with sounds; four were found to have large atonic bladders. Following dilatation there was an $80 \%$ improvement in symptomatology. One patient who had had chronic cystitis for eight years, fully investigated in two hospitals, has been symptom-free for three years. A control group of 20 patients who had never had cystitis or difficulty in micturition were able to aim a firm stream of urine and did not report any marked spraying.

The results suggest that urethral stricture is more common than supposed and erect micturition is a simple way of suspecting this in general practice.

I am very grateful for the encouragement of Professor J. P. Blandy in composing this letter. -I am, etc.,

Byfield,

J. A. Holland

Daventry, Northants

Rosette-forming T-lymphocytes in Malnutrition

SIR,-We were interested in the preliminary communication by Professor R. K. Chandra (7 September, p. 608) dealing with rosetteforming $\mathrm{T}$-lymphocytes and cell-mediated immunity in malnutrition. We have performed similar investigations on children with protein-calorie malnutrition and oedema (kwashiorkor), and though we have previously confirmed depressed lymphocyte transformation to phytohaemagglutinin (PHA) in these children ${ }^{1}$ we have found normal percentages of rosette-forming $T$ lymphocytes in their peripheral blood.

Fifteen patients with kwashiorkor (Wellcome criteria ${ }^{2}$ ) were studied at the time of admission to determine percentages of rosette-forming cells in peripheral blood. The age of the patients was from 6 months to 2 years and 10 well-nourished children of a similar age range, admitted to hospital with infections or for elective orthopaedic procedures, served as controls. Spontaneously rosetting $\mathrm{T}$-lymphocytes were detected by the method of Jondal et al. ${ }^{3}$ after lymphocyte purification using gelatin and carbonyl iron. The technique was checked daily with a normal adult control (normal range $50-70 \%$ ).

As can be seen in the accompanying figure no significant difference exists between the percentages of $T$-lymphocytes in the peripheral blood of the malnourished and the control groups $(P>0 \cdot 2)$. These discrepancies could reflect differences in case material in that the children in Professor Chandra's series were more marasmic than ours and only two were oedematous. Similarly the ages of the patients in the former series were not indicated.

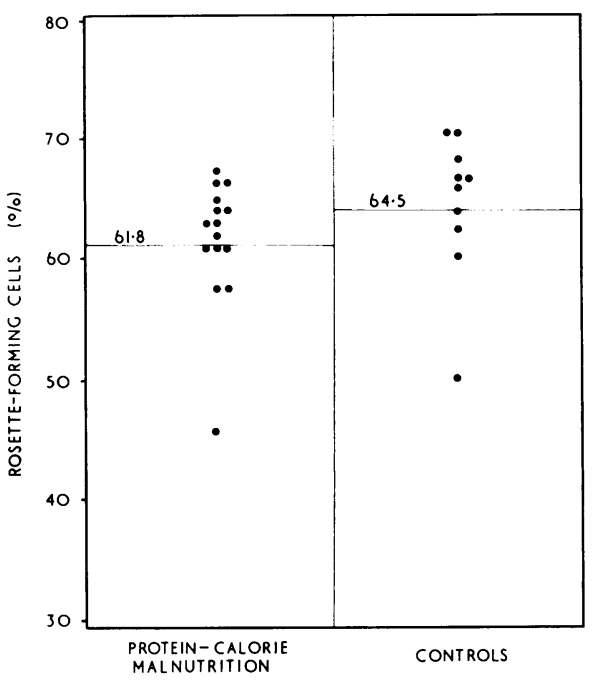

It is of interest that a recent study of cellmediated immunity in children with proteincalorie malnutrition ${ }^{4}$ indicated a correlation between depressed ${ }^{3} \mathrm{H}$-thymidine uptake and folate deficiency. This finding would suggest that impaired lymphocyte response to PHA in these children is due to a qualitative lymphocyte defect rather than due to a quantitative reduction in $\mathrm{T}$-lymphocyte numbers.

This work was supported by a grant from the South African Medical Research Council. We are, etc.

A. R. RABSON

J. GEEFHUYZEN

E. U. ROSEN M. JOFFE

Departments of Microbiology and Paediatrics,

School of Pathology

Baragwanath Hospital and the University of the

Witwatersrand,

Johannesburg, South Africa

1 Geefhuysen, J., British Medical fournal, 1971, 4,527

3 Lancet, 1970, 2, 302 . G., and Wigzell, H., fournal ondal, M., Holm, G., and Wigzell, H.,
of Experimental Medicine, 1972, 136, 207 Burgess, B. J., et al., South African Medica!
fournal, 1974, 48, 1870.

\section{Agoraphobia}

SIR,-Like Dr. D. E. I. Friedman and Dr. A. G. Zermansky (23 November, pp. 467 and 468) I was disappointed in your leading article (26 October, p. 177). The syndrome of agoraphobia is multi-faceted ${ }^{1}$ and represents in some the aftermath of a depressive illness frequently still unresolved when treatment for the phobia is requested. In others it consists of maladaptive conditioned responses maintained by habit, while still other sufferers are prone to a variety of psychological conflicts and primary or secondary gains that play an integral part in the formation and maintenance of phobic symptoms. Snaith ${ }^{2}$ went so far as to suggest dropping the term agoraphobia and substituting "non-specific insecurity fears." Certainly in each case an attempt must be made to understand the illness in the light of past and current life events and to explore the particular meaning and significance of symptoms for the individual. To advocate controlled prospective trials of, for instance, psychosurgery, which at present oocupies a very insignificant role in treatment, for patients with such disparate aetiologies and needs seems crude and inappropriate. Furthermore, I was surprised by your inference that by "psychological measures" solely behavioural techniques were meant, thus taking no account of the uncovering of motivation through insight therapy. As Dr. Friedman points out, the results of behaviour therapy in agoraphobics are significantly improved when practised in conjunction with interpretative psychotherapy.

Preliminary analysis of 68 personal cases of agoraphobia yielded $56 \%$ in whom factors of psychological gain prevented success with deconditioning; half of these subsequently responded satisfactorily to the same measures when insight had been gained into psychological difficulties and appropriate emotional readjustments made. While it is not enough to deal with conflicts, relationship problems, and psychological gains alone, however, and it is evident that patients have to face the phobic situation before they can improve, the converse seems equally applicable in a considerable proportion.

As a founder member of the Phobics Society, Manchester, I am of course in agreement that self-help groups of sufferers can be extremely valuable, but to equate, as you do, the support they offer with the highly structured, systematic programme of group flooding, carried out by a trained nurse therapist with the backing of the parent hospital, is hardly justifiable. Recent clinical experience indeed confirms that cohesive group flooding in vivo ${ }^{3}$ is the most realistic (in terms of staff time) and also the most successful behaviour therapy for this at times intractable disorder.-I am, etc.,

SUSANNE SHAFAR

Psychiatric Day Department,

Crumpsall Hospital,
Manchester

1 Marks, I. M., British fournal of Psychiatry, 1970 , 116. 377. P. British fournal of Psychiatry, 1968,
nnaith, R. P., 114, 673 .

British I., Lamontagne, Y., and Marks, I. M. British fournal of Psychiatry, 1974, 124, 588.

Economies in the N.H.S.

SIR,-With regard tu Dr. D. Atkinson's letter (16 November, p. 406) commenting that an apparently mobile patient attended surgery on foot and said that the hospital had told him to contact his G.P., who would order an ambulance for subsequent conveyance to hospital, I would like to point out that the position from the ambulance service point of view is as follows.

The procedure supported by the Department of Health and Social Security for the conveyance by ambulance of outpatients is that the G.P. orders the ambulance for the first visit to hospital (having, of course, satisfied himself that no other means of transportation is feasible). After the first visit subsequent authorization for ambulance transport must be made by the hospitalthat is, authorization must originate from the source where treatment is given. In the case in question the G.P. had the right to refuse ambulance transport and his only action to assist the patient would have been to question the case with the appropriate clinic at the hospital.-I am, etc.,

L. LORD Regional Ambulance Officer Harrogate 